\title{
Estimating and Comparing the Term Structure of Interest Rates for Assets with Frequent and Infrequent Trading
}

\author{
Andre Luiz Carvalhal da Silva ${ }^{*}$ and Bernardo Ribeiro da Silva
}

Coppead Graduate School of Business, Federal University of Rio de Janeiro, Brazil

\begin{abstract}
Traditional methods of modeling and estimating the term structure of interest rates assume that bonds are frequently traded and have a complete data set. In this paper, we use the Kalman filter approach to estimate and compare the term structure of assets with complete and sparse data set in the same country. Brazil offers a unique case study because the stock of government bonds is one of the largest in the world. We test for two types of financial assets: government bonds (which are characterized by infrequent trading) and One-Day Interbank Deposit Futures (which are the most liquid interest rate derivative in the Brazilian market). Our results indicate that the model performs well in fitting observed yields of both government bonds and interest rates futures contracts. Most importantly, out-of-sample errors for government bonds are very close to those of interest rates futures contracts, which suggests that the model can be successfully used for forecasting yield curves of sporadically traded assets.
\end{abstract}

Keywords: Term-structure estimation, infrequent trading, emerging markets, Brazil.

\section{INTRODUCTION}

The analysis of the term structure of interest rates has been performed using two main objectives. First, there are studies that model and estimate the current term structure of spot rates using parametric and non-parametric methods [15]. Second, a vast literature models the dynamics of the term structure and its movement across time [6-10].

Recent literature has used the Kalman filter for dynamic models of interest rates [11-16]. This method can be successfully used when there are a sufficient number of price observations; otherwise it produces unreliable results. Cortazar et al. [17] modify the standard Kalman filter approach and develop a method for jointly estimating the current term structure and its dynamics in markets with infrequent trading.

In this article we implement the method developed by Cortazar et al. [17] using Brazilian data. We test for two types of financial assets: government bonds (which are characterized by infrequent trading) and One-Day Interbank Deposit Futures (which are the most liquid interest rate derivative in the Brazilian market). We innovate by analyzing and comparing the term structure estimation of assets with complete and sparse data set in the same country.

Brazil offers a unique case study because the stock of government bonds is one of the largest in the world. Although the size of this market is not particularly large in developing countries, the size of the Brazilian government bond market is larger than other developing and even developed markets. In December 2005, the proportion of the domestic government bonds relative to GDP was 36\% in Latin America, 27\% in East Asia, 59\% in developed countries, and $47 \%$ in Brazil.

\footnotetext{
*Address correspondence to this author at the Coppead Graduate School of Business, Federal University of Rio de Janeiro, Brazil;

E-mail: andrec@coppead.ufrj.br
}

Overall, our results indicate that the model performs well in fitting observed yields of both government bonds and interest rates futures contracts. As expected, measurement errors of government bonds are higher than those of interest rates futures contracts, which is consistent with the infrequent trading of government bonds. Nevertheless, out-ofsample error measures for government bonds are very close to those of interest rates futures contracts, which suggests that the model can be successfully used for forecasting yield curves of sporadically traded assets.

Next section discusses the assumptions of the generalizedVasicek model under infrequent trading. Section 3 presents the Kalman filter estimation with incomplete panel-data. Section 4 describes the data and explains the methodology used for complete and incomplete panel-data setting. Section 5 presents empirical results for Brazilian government bonds and interest rates futures contracts. Section 6 concludes.

\section{GENERALIZED-VASICEK MODEL UNDER INFRE- QUENT TRADING}

A generalized-Vasicek model is a multifactor meanreverting Gaussian model of the instantaneous spot interest rate that extends Vasicek [6]. Vasicek's basic assumptions are: (i) the spot rate follows a continuous Markov process; (ii) the price $P(t, s)$ at time $t$ of a pure discount bond which matures at time $s(t \leq s)$ is determined by the assessment at time $t$, of the segment $\{r(\tau), t \leq \tau \leq s\}$ of the spot rate process over the term of the bond; and (iii) the market is efficient and investors act rationally.

The first assumption implies that the spot interest rate $r(t)$ can be written in the form of a stochastic differential equation

$$
d r=f(r, t) d t+\rho(r, t) d z
$$

where $z(t)$ is a Wiener process with incremental variance $d t$, $f(r, t)$ and $\rho^{2}(r, t)$ are the instantaneous drift and variance of the process $r(t)$, respectively. 
The second assumption implies that the bond price is a function of $t, s$ and $r(t)$. The development is completed by invoking the last assumption to prevent riskless arbitrage by reasoning similar to that used to derive the Black Scholes option pricing formula.

The Kalman filter algorithm has been used in the evaluation of the exact likelihood function of the observed interest rates and the computation of the unobserved state variables and parameters of the model. State-space models allow for measurement errors in the observed yields to maturity, and are therefore useful for simultaneous estimation using yields on many bonds with different maturities.

Generally, the Kalman filter requires a complete panel of bond prices (or yields). When there are sparse bond price data, two problems may occur: insufficient number of observations and/or insufficient short and long-term bonds.

In low-liquidity markets, we should perform a two-stage approach to construct the yield curve. First, we make predictions for unobserved prices, and then fit the yield curve on basis of observed market prices and predictions for unobserved market prices. Cortazar et al. [17] have modified the Kalman filter approach to deal with the missing observation problem. They propose to solve the problems of term-structure estimation in markets with infrequent trading by using also past price information to infer the current term structure.

They illustrate the estimation methodology using a generalized Vasicek model for the instantaneous risk-free interest rate. It is interesting to note that their method does not violate any assumption made by Vasicek [6]. Although they use sparse bond price data, all three Vasicek's assumptions are still valid.

First, the spot rate still follows a continuous Markov process. The spot rate is defined as the instantaneous borrowing and lending rate

$$
r(t)=R(t, 0)=\lim _{T \rightarrow 0} R(t, T)
$$

where $R(t, T)$ is the internal rate of return at time $t$ on a bond with maturity date $s=t+T$. Sparse bond price data are not in conflict with the assumption of a continuous Markov process of the spot rate. Infrequent trading has to deal with insufficient number of observations, but not with the continuity process of the spot rate. By the first assumption, the development of the spot rate process over an interval $(t, s), t \leq s$, given its values prior to time $t$, depends only on the current value $r(t)$.

Second, the price $P(t, s)$ of a pure discount bond is still determined by the assessment at time $t$ of the spot rate process over the term of the bond. This implies that the bond price is a function of $t, s$ and $r(t)$. Thus, the value of the spot rate is the only state variable for the whole term structure.

Third, the assumption of market efficiency and investor rationality continues to hold, that is, there are no transactions costs, and every investor acts rationally and uses all available information.

Although an incomplete panel of bond prices does not violate Vasicek's basic assumptions, it may cause problems for the term-structure estimation. One possible solution is to use past price information when current information is not available. In this case, we need a dynamic model of the sto- chastic behavior of interest rates to mix current and past prices in a meaningful way. Next section presents the Kalman filter approach proposed by Cortazar et al. [17] to deal with the missing observation problem.

\section{KALMAN FILTER ESTIMATION WITH INCOM- PLETE PANEL-DATA}

In this section we present a very brief description of Kalman filter estimation with incomplete panel-data. For a detailed explanation, see Cortazar et al. [17].

The Kalman filter has been widely used in finance, especially to estimate stochastic models of interest rates $[12,13$, $15,16,18,19]$. Most previous studies do not analyze markets with infrequent trading and apply Kalman filter to complete panel data set.

However, there are examples of works that have applied Kalman filter for incomplete panel-data (Sørensen [20] in the commodity market, and Cortazar et al. [17] in the interest rate markets). In fact, Cortazar et al. [17] show that a natural extension of the standard Kalman filter may be applied to jointly estimate the current term structure and its dynamics in markets with infrequent trading.

The Kalman filter is essentially a set of mathematical equations that can be applied in models that are in a statespace representation. The measurement equation relates observable variables with state (generally not observable) variables, whereas the transition equation describes the dynamics of the state variables. The Kalman filter provides optimal estimates of the state variables.

Cortazar et al. [17] show that is not necessary to assume a fixed number of observable variables at each time period in order to apply the Kalman filter. Let $m_{t}$ be the number of observations at time $t$, which can differ from the number of observations available at any other date. At each point in time, the measurement equation relates a vector of observable variables $\mathrm{z}_{t}$ with a vector of state variables $\mathrm{x}_{t}$.

$$
\mathrm{z}_{t}=\mathrm{H}_{t} \mathrm{x}_{t}+\mathrm{d}_{t}+\mathrm{v}_{t}
$$

where $\mathrm{z}_{t}$ is a $m_{t} \mathrm{x} 1$ vector, $\mathrm{H}_{t}$ is a $m_{t} \mathrm{x} n$ matrix, $\mathrm{x}_{t}$ is a $n \mathrm{x}$ 1 vector, $\mathrm{d}_{t}$ is a $m_{t} \times 1$ vector and $\mathrm{v}_{t}$ is a $m_{t} \times 1$ vector of serially uncorrelated Gaussian disturbances with mean 0 and covariance matrix $\mathrm{R}_{t}$ with $m_{t} \times m_{t}$ dimension. Under these assumptions, there is an incomplete panel-data set.

Given a vector of state variables $\mathrm{x}_{t-1}$ and a covariance matrix $\mathrm{P}_{t-1}$ of the estimation errors, the filter first calculates a prediction of the state variables $x_{t \mid t-1}$ and of the covariance matrix $\mathrm{P}_{t \mid t-1}$ of the errors using the dynamic properties of the state variables, which do not depend on the number of observable variables.

Then the filter incorporates the new information given by $z_{t}$. Since the Kalman filter computes at every date the conditional expectation $\mathrm{x}_{t}$, the estimates can still be computed, even if the number of observations vary with time. It is important to note that the greater the number of observations the better the estimation accuracy.

\section{DATA AND METHODOLOGY}

Brazilian Treasury issues two types of securities to finance its debt: bills and notes. All of them are issued through an electronic system under Central Bank administration. 
Treasury Bills are called LTN (Letras do Tesouro Nacional) or LFT (Letras Financeiras do Tesouro). LTNs do not have coupon and are sold by discount. LFTs do not have coupon, are sold by discount, but are indexed at daily floating rates to be paid at the end of maturity. Since Plano Real was launched, Brazilian Treasury has been issuing more frequently LTNs as the main instrument to finance its deficit. On its turn, LFTs have been issued in volatile periods. Nowadays, LTNs and LFTs are currently issued with maturities up to 2 and 7 years, respectively.

Notes are called NTN (Notas do Tesouro Nacional). NTNs are generally indexed, and the indexes depend on each series. They were designed to have longer maturities than bills. Nevertheless, they have been issued with either shortterm or long-term. They usually pay semi-annual coupon, and can be sold with original-issue maturity until 30 years.

In this paper, we analyze LTNs, because they are the most liquid Brazilian government bonds. Besides LTNs, we also analyze the ID-Future (DI Futuro), which is a futures contract whose underlying asset is the accumulated daily ID rate (one-day interbank borrowing/lending rate).

The ID-Future is very similar to a zero coupon bond, except that it pays margin adjustments every day. The contract size corresponds to R $\$ 100,000.00$ (one hundred thousand Brazilian reais) discounted by the accumulated rate negotiated between the buyer and the seller of the contract. Each daily cash flow is the difference between the settlement price on the current day and the settlement price on the day before corrected by the ID rate of the day before.

The Brazilian Mercantile and Futures Exchange (BM\&F) is the entity that offers the ID-Future. The number of authorized contract-maturity months is fixed by BM\&F (on average, there are about 20 contract-maturity months for each day but only around 10 are liquid). Contract-maturity months are the first four months subsequent to the month in which a trade has been made and, after that, the months that initiate each following quarter. Expiration date is the first business day of the contract maturity month.

Our data consist on time series of yields of LTNs and IDFutures for different maturities. The data on LTN is obtained from the Brazilian Central Bank, whereas the data on IDFuture come from BM\&F.

We estimate a one-factor generalized-Vasicek model using LTN and ID-Future data from January 02, 2003 to December 31, 2007. A generalized-Vasicek model is a multifactor mean-reverting Gaussian model of the spot interest rate that extends Vasicek [6]. We also estimate the model with two and three factors, but the results (not reported but available upon request) are substantially the same. One possible explanation is that most yield variation can be explained by the first factor. This is consistent with Litterman and Scheinkman [21], who show that $90 \%(98 \%)$ of U.S. bond variation can be explained by one (three) principal components. In the case of Brazil, our results indicate that the one factor can explain almost $95 \%$ of yield variation for some maturities.

We follow Cortazar et al. [17] and use the Kalman filter to estimate the unobservable state variables and the model parameters. We aggregate LTNs and ID-Futures into groups depending on their maturities: up to 1 month, from 1 to 3 months, from 3 to 6 months, from 6 to 9 months, from 9 to 12 months, from 12 to 24 months, and higher than 24 months. We group the observations longer than 24 months together, because LTNs and ID-Futures are generally shortterm instruments.

Tables $\mathbf{1}$ and $\mathbf{2}$ summarize the data. Trading frequency is measured as the number of days with at least one trade of LTNs or ID-Futures of a specific maturity over all available trading days from January 02, 2003 to December 31, 2007.

Except for maturities up to 1 month and higher than 24 months, the trading frequency for LTNs and ID-Futures is high, ranging from $85 \%$ to $95 \%$ (LTNs) and from $99 \%$ to $100 \%$ (ID-Futures). In contrast, the trading frequency decreases for maturities up to 1 month $(14 \%$ for LTNs and $41 \%$ for ID-Futures) and higher than 24 months (44\% for LTNs and $83 \%$ for ID-Futures). This result clearly indicates that LTNs and ID-Futures are short-term instruments.

Table 1. Daily Transactions of Brazilian Government Bonds (LTN) from Jan 2003 to Dec 2007

\begin{tabular}{|c|c|c|c|}
\hline $\begin{array}{c}\text { Maturity } \\
\text { Range } \\
\text { (Months) }\end{array}$ & $\begin{array}{c}\text { Number of } \\
\text { Observations }\end{array}$ & $\begin{array}{c}\text { Average Trading } \\
\text { Frequency (\%) }\end{array}$ & $\begin{array}{c}\text { Average Daily } \\
\text { Volume } \\
\text { (R\$ Million) }\end{array}$ \\
\hline \hline $0-1$ & 179 & 14.3 & $1,014.10$ \\
\hline $1-3$ & 1,195 & 93.8 & $1,045.32$ \\
\hline $3-6$ & 1,203 & 94.3 & $1,981.81$ \\
\hline $6-9$ & 1,206 & 94.6 & $1,234.51$ \\
\hline $9-12$ & 1,079 & 84.9 & 690.51 \\
\hline $12-24$ & 2,336 & 86.9 & $1,234.45$ \\
\hline $24-$ Higher & 605 & 43.7 & 543.64 \\
\hline
\end{tabular}

Table 2. Daily Transactions of 1-Day Interbank Deposit Future (ID-Future) from Jan 2003 to Dec 2007

\begin{tabular}{|c|c|c|c|}
\hline $\begin{array}{c}\text { Maturity } \\
\text { Range } \\
\text { (Months) }\end{array}$ & $\begin{array}{c}\text { Number of } \\
\text { Observations }\end{array}$ & $\begin{array}{c}\text { Average Trading } \\
\text { Frequency (\%) }\end{array}$ & $\begin{array}{c}\text { Average Daily } \\
\text { Volume } \\
\text { (R\$ Million) }\end{array}$ \\
\hline \hline $0-1$ & 508 & 41.0 & $2,699.67$ \\
\hline $1-3$ & 3,697 & 100.0 & $10,993.58$ \\
\hline $3-6$ & 1,686 & 99.1 & $8,766.51$ \\
\hline $6-9$ & 1,243 & 99.1 & $7,295.59$ \\
\hline $9-12$ & 1,243 & 99.1 & $4,479.52$ \\
\hline $12-24$ & 4,406 & 100.0 & $9,905.06$ \\
\hline $24-H i g h e r$ & 9,767 & 82.5 & $5,477.60$ \\
\hline
\end{tabular}

The average daily volume for ID-Futures (ranging from R \$ 2.70 billion to R \$ 10.99 billion) is higher than that of LTNs (ranging from R $\$ 543.64$ million to R $\$ 1.98$ billion). Although the LTN is the most liquid government bond traded in Brazil, its liquidity is very small when compared to ID-Futures. 
Despite its low liquidity, the secondary market for LTNs has developed since 2003. As can be seen in Fig. (1), the total trading volume of LTNs increased from R\$ 89.64 billion in the first semester of 2003, reached the peak (R\$ 1.27 trillion) in the second semester of 2004, and decreased to R\$ 716.67 billion in the second semester of 2007 . The time to maturity of LTNs increased from 150 days in 2003 to 225 days in 2007.

The liquidity increase of LTNs when compared to the levels of 2003 can be attributed to the efforts of the Brazilian National Treasury to develop the secondary market of government bonds. Further, most internal and international crises occurred before 2003 (Asia in 1997, Russia in 1998, Brazilian currency devaluation in 1999 and pre-election turmoil in 2002), which affected negatively the liquidity of Brazilian domestic and international bonds.

Fig. (2) shows that the secondary market of ID-Futures has increased recently. The total trading volume increased from R\$ 2.18 trillion in the first semester of 2003 to $\mathrm{R} \$ 8.70$ trillion in the second semester of 2007. The average maturity of ID-Futures increased from 110 days in 2003 to 316 days in 2007. This behavior is very similar to that of LTNs and is caused by the same internal and international factors.

Table 3 reports that the total trading volume of LTNs increased from 2003 to 2004 , but has decreased since then in both absolute and relative terms when compared to that of ID-Futures. When we analyze the trading volume of both markets together, LTNs represented $4 \%$ of the total at the beginning of 2003; increased to $22.5 \%$ at the end of 2004 ; and decreased to $7.6 \%$ at the end of 2007 .
Table 3. Total Trading Volume of Brazilian Government Bonds (LTN) and 1-Day Interbank Deposit Future (ID-Future) from Jan 2003 to Dec 2007

\begin{tabular}{|c|c|c|c|c|}
\hline Date & LTN (R\$ Billion) & $\begin{array}{c}\text { ID-Future } \\
\text { (R\$ Billion) }\end{array}$ & LTN (\%) & ID-Future (\%) \\
\hline \hline 1S 03 & 89.64 & $2,178.96$ & 4.0 & 96.0 \\
\hline 2S 03 & 333.76 & $3,064.43$ & 9.8 & 90.2 \\
\hline 1S 04 & 695.32 & $4,859.40$ & 12.5 & 87.5 \\
\hline 2S 04 & $1,271.76$ & $4,385.74$ & 22.5 & 77.5 \\
\hline 1S 05 & $1,035.68$ & $4,610.50$ & 18.3 & 81.7 \\
\hline 2S 05 & 964.03 & $6,158.17$ & 13.5 & 86.5 \\
\hline 1S 06 & 837.18 & $6,642.91$ & 11.2 & 88.8 \\
\hline 2S 06 & 884.12 & $7,554.65$ & 10.5 & 89.5 \\
\hline 1S 07 & 775.64 & $10,559.45$ & 6.8 & 93.2 \\
\hline 2S 07 & 716.67 & $8,701.90$ & 7.6 & 92.4 \\
\hline
\end{tabular}

Figs. (3) and (4) illustrate the trading frequency of daily transactions by showing for each day when a LTN or IDFuture was traded or not. A black cell indicates that there was a trade for the corresponding maturity at a given day. We can note that the LTN trades only sporadically, and its panel-data is clearly incomplete. In contrast, the ID-Future can be characterized as a market with frequent trading.

A problem that can occur in markets with infrequent trading (e.g. LTNs) is that an infinite number of curves can fit the observed yields due to the low number of transactions. If

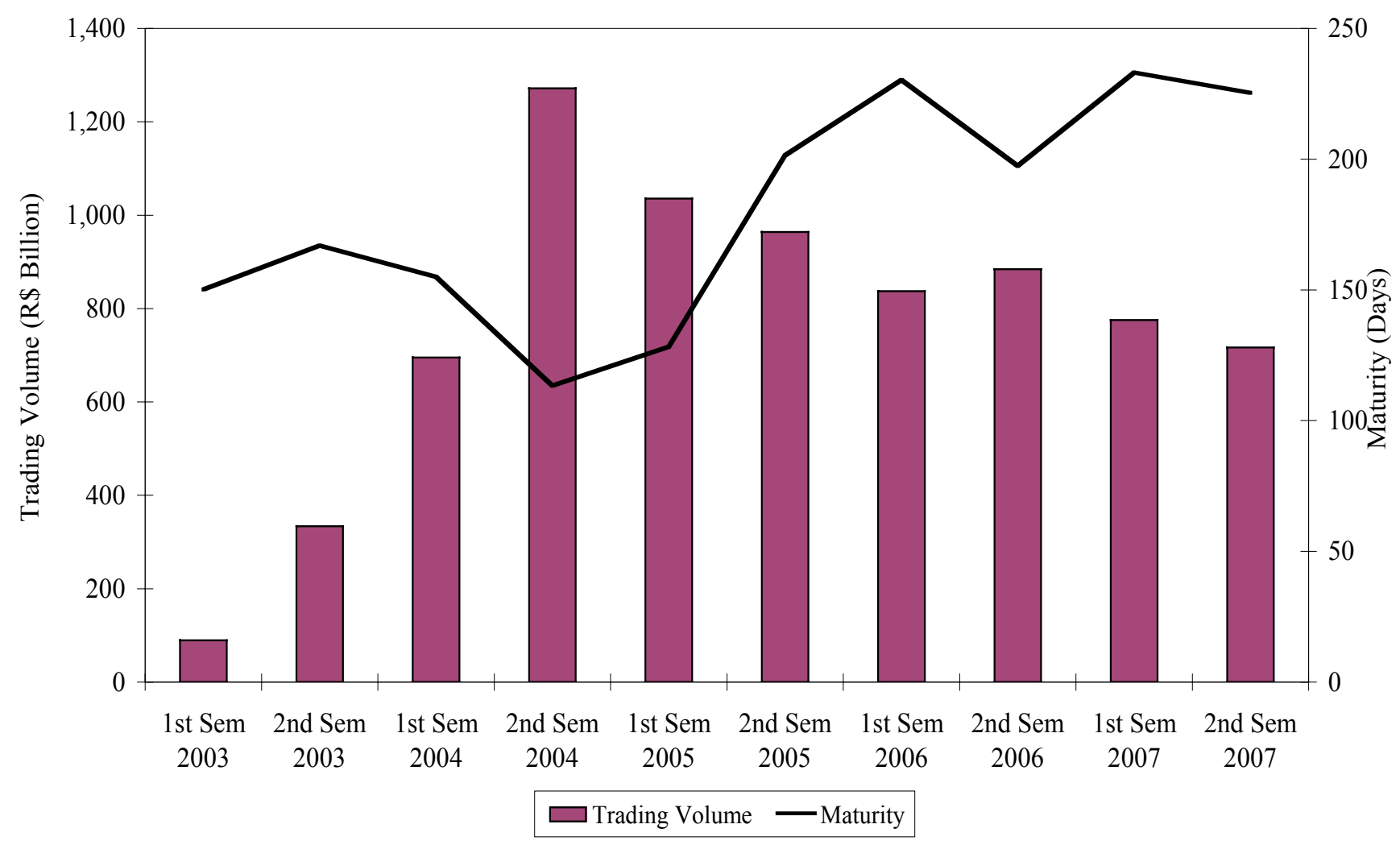

Fig. (1). Total Trading Volume of Brazilian Government Bonds (LTN) from 2003 to 2007. 


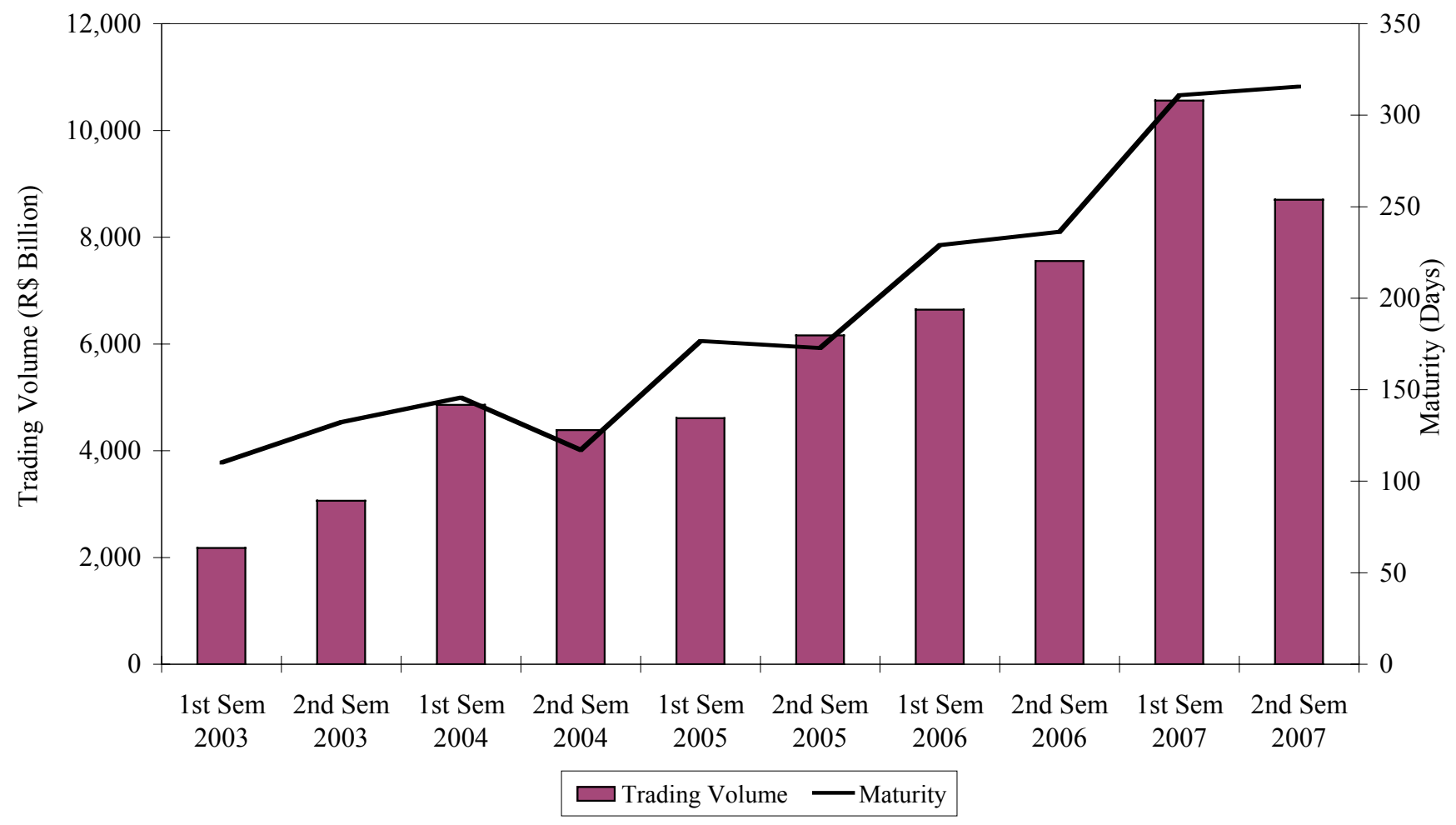

Fig. (2). Total Trading Volume of 1-Day Interbank Deposit Future (ID-Future) from 2003 to 2007.

the number of observed yields is not sufficiently larger than the number of parameters to be estimated, measurement errors can affect the shape of the fitted curve. Fig. (5) plots two possible term-structures that perfectly explain observed yields of LTNs in December 2007.

\section{ESTIMATION RESULTS}

Application of the Kalman fiter to the one-factor Vasicek model parameters using LTN and ID-Futures data from January 2003 to December 2007 are now discussed. The

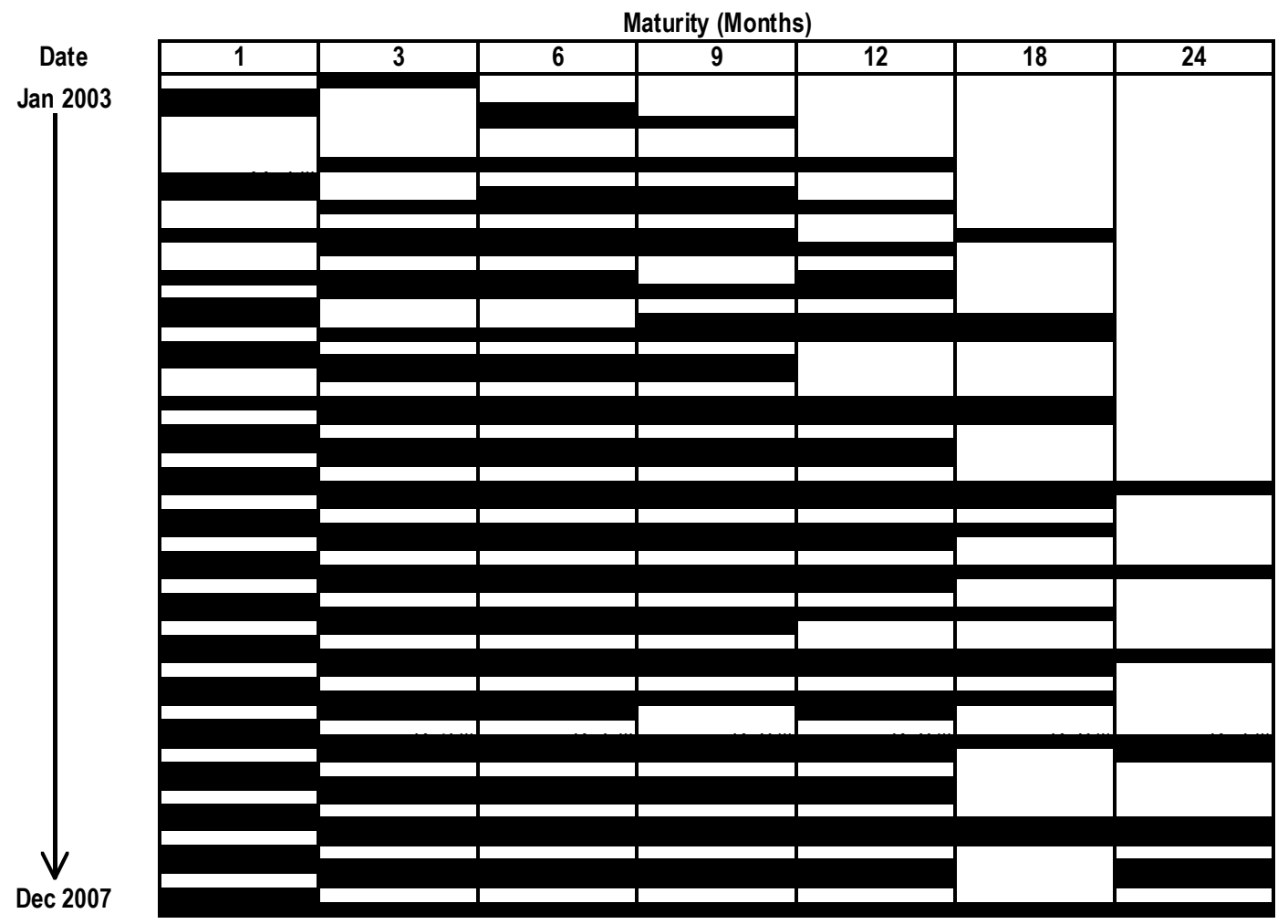

Fig. (3). Trading Frequency of Daily Transactions of Brazilian Government Bonds (LTN) from 2003 to 2007. 


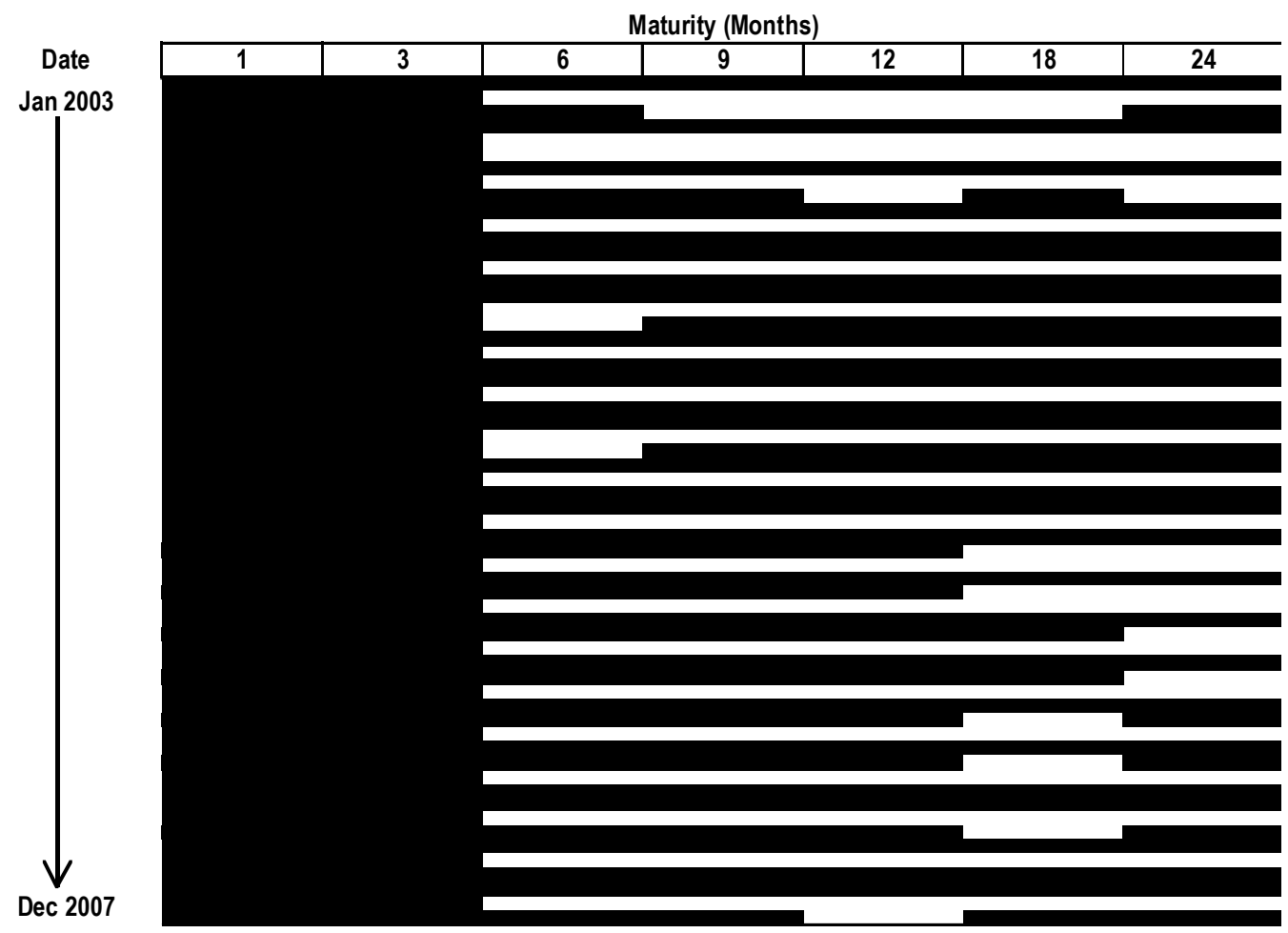

Fig. (4). Trading Frequency of Daily Transactions of 1-Day Interbank Deposit Future (ID-Future) from 2003 to 2007.

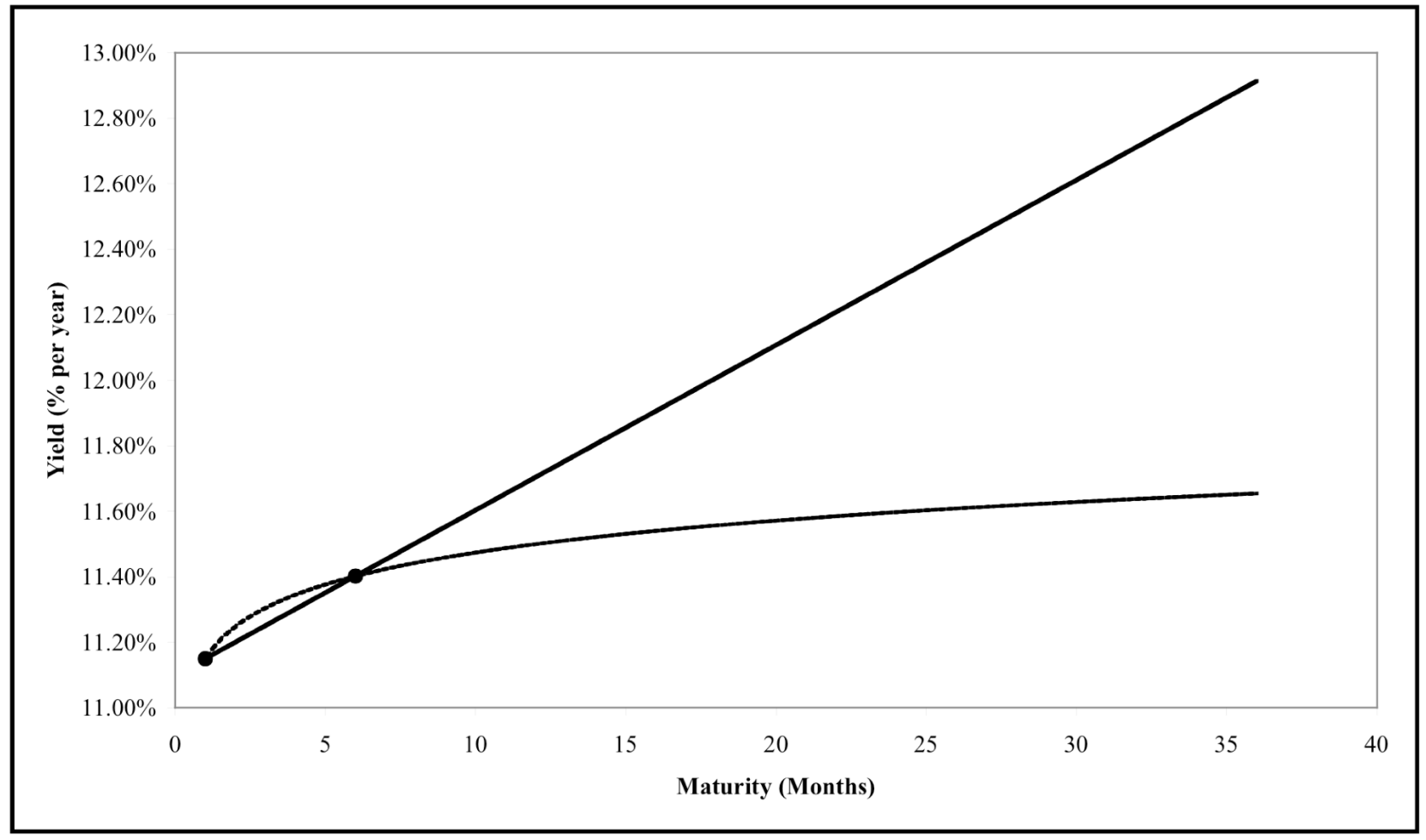

Fig. (5). Two Estimations of Yield Curves for Brazilian Government Bonds (LTN) Using Polynomial and Logarithmic Interpolation in December 2007.

estimation results are presented in Tables $\mathbf{4}$ and $\mathbf{5}$, which contains the parameter estimates of $\kappa$ (mean reversion rate), $\theta$ (long-run average rate), $\sigma$ (diffusion coefficient), $\lambda$ (risk premium), and the estimated standard deviations of the measurement errors $\left(\mathrm{s}_{1}, \mathrm{~s}_{2}, \mathrm{~s}_{3}, \mathrm{~s}_{4}, \mathrm{~s}_{5}\right.$, and $\left.\mathrm{s}_{6}\right)$ related to each of the 6 groups of LTNs and ID-Futures (up to 1 month, from 1 to 3 months, from 3 to 6 months, from 6 to 9 months, from 9 to 12 months, and from 12 to 24 months). LTNs and IDFutures within each group are assumed to have measurement errors with the same standard deviation. Standard errors are computed using the formulae in Hamilton [22]. The tables also contain the log-likelihood value. 
Table 4. Parameter Estimates of the Vasicek Model from Daily Transactions of Brazilian Government Bonds (LTN) from Jan 2003 to Dec 2007

\begin{tabular}{|c|c|c|c|}
\hline Parameter & Estimate & Standard Error & $t$ Statistics \\
\hline \hline$\kappa$ & 0.2567 & 0.0575 & 4.4644 \\
\hline$\theta$ & 0.1533 & 0.0215 & 7.1203 \\
\hline$\sigma$ & 0.0181 & 0.0027 & 6.7830 \\
\hline$\lambda$ & -0.5046 & 0.3384 & -1.4911 \\
\hline $\mathrm{s}_{1}$ & 0.0120 & 0.0019 & 6.3269 \\
\hline $\mathrm{S}_{2}$ & 0.0035 & 0.0005 & 6.5067 \\
\hline $\mathrm{S}_{3}$ & 0.0008 & 0.0011 & 0.7627 \\
\hline $\mathrm{s}_{4}$ & 0.0028 & 0.0005 & 5.5931 \\
\hline $\mathrm{S}_{5}$ & 0.0055 & 0.0013 & 4.3465 \\
\hline $\mathrm{s}_{6}$ & 0.0076 & 0.0019 & 4.0584 \\
\hline $\log \mathrm{L}$ & 83.51 & & \\
\hline
\end{tabular}

Table 5. Parameter Estimates of the Vasicek Model from Daily Transactions of 1-Day Interbank Deposit Future (ID-Future) from Jan 2003 to Dec 2007

\begin{tabular}{|c|c|c|c|}
\hline Parameter & Estimate & Standard Error & $t$ Statistics \\
\hline \hline$\kappa$ & 0.2253 & 0.0432 & 5.2165 \\
\hline$\theta$ & 0.1493 & 0.0202 & 7.4021 \\
\hline$\sigma$ & 0.0156 & 0.0020 & 7.6172 \\
\hline$\lambda$ & -0.3580 & 0.3110 & -1.1511 \\
\hline $\mathrm{s}_{1}$ & 0.0006 & 0.0008 & 0.7435 \\
\hline $\mathrm{s}_{2}$ & 0.0002 & 0.0003 & 0.6786 \\
\hline $\mathrm{s}_{3}$ & 0.0000 & 0.0009 & 0.0394 \\
\hline $\mathrm{s}_{4}$ & 0.0003 & 0.0004 & 0.6289 \\
\hline $\mathrm{s}_{5}$ & 0.0005 & 0.0009 & 0.6011 \\
\hline $\mathrm{s}_{6}$ & 0.0006 & 0.0010 & 0.6181 \\
\hline $\log \mathrm{L}$ & 218.60 & & \\
\hline
\end{tabular}

Overall, the results for LTNs and ID-Futures are similar. However, the measurement errors of the LTNs are higher than those of ID-Futures. Further, the log-likelihood value increases strongly as we move to ID-Futures. This result is not surprising, because ID-Futures are characterized by frequent trading (complete data set), whereas LTNs are characterized by infrequent trading (sparse data set). When a reduced number of observations is available at some date, the estimation error is greater, reflecting more uncertainty on the true value of the state variables.

The mean reversion rate, long-run average, and diffusion parameters are significant for both LTNs and ID-Futures. The mean reversion parameters imply mean half-lives for both interest rate processes (i.e. the expected time for the process to return halfway to its long-term mean) of 3 years.
In contrast to the significant estimates of $\kappa, \theta$, and $\sigma$, the risk premium $\lambda$ is not significant, indicating that parallel shifts in the yield curve have not been priced. This result may be due to the different nature of the markets and maturities used in the empirical analysis.

The measurement errors are significant for LTNs, but they are not significant for ID-Futures. The standard deviation of the measurement errors in the LTN model for the 1month rate is 120 basis points and 35 basis points for the 3 month rate. This compares to 6 basis points and 2 basis points in the ID-Futures model. For the 6-month rate the LTN model has a measurement error of 8 basis points compared to less than one basis point in the ID-Future model. They are 28 basis points for the 9 -month rate, 55 basis points for the 12-month rate, and 76 basis points for the 24-year rate in the LTN model. This compares to 3 basis points for the 9-month rate, 5 basis points for the 12-month rate, and 6 basis points for the 24-month rate in the ID-Futures model.

In Fig. (6), we have plotted the yield curves derived from the model for LTNs and ID-Futures in December 2007, and compared them to the observed yields for a selection of maturities across the curve. The results reveal that the model correctly fits observed yields, and tracks most of the turning points over the sample period.

Tables 6 and 7 show in-sample and out-of-sample error measures (RMSE) by maturity for the year 2007. We calculate out-of-sample RMSE by re-estimating the model using data from 2003 to 2006, and then comparing estimated and observed yields for the year 2007. We can see that all errors are relatively low compared to the high levels of Brazilian interest rates in 2007 (around 11.5\% per year). Further, errors for short-term bonds are larger than for long-term bonds, which is consistent with the results of Cortazar et al. [17] for the Chilean market.

As expected, out-of-sample errors are higher than insample errors. Further, error measures of LTNs are higher than those of ID-Futures, which are caused by the infrequent trading of LTNs. Although the errors are higher for LTNs compared to ID-Futures, the out-of-sample RMSE for LTNs is very close to that of ID-Futures, which indicates that the estimation method applied in the paper can be successfully used for forecasting yield curves of sporadically traded assets.

Overall, this paper indicates that the extended Kalman filter approach proposed by Cortazar et al. [17] can be used to estimate the current term structure in markets with infrequent trading. This situation is very common in many emerging markets, in which bonds trade sporadically so that there are bond prices for only a few maturities. Although we implement the approach using a one-factor generalized-Vasicek model and Brazilian data, the methodology can be implemented with a broad class of interest rate models and in any market with infrequent trading.

\section{CONCLUSIONS}

A vast literature estimates and models the dynamics of the term structure of interest rates. The Kalman filter has been used for dynamic models of interest rates when bonds are frequently traded and have a complete data set. In this paper, we implement the method developed by Cortazar et 


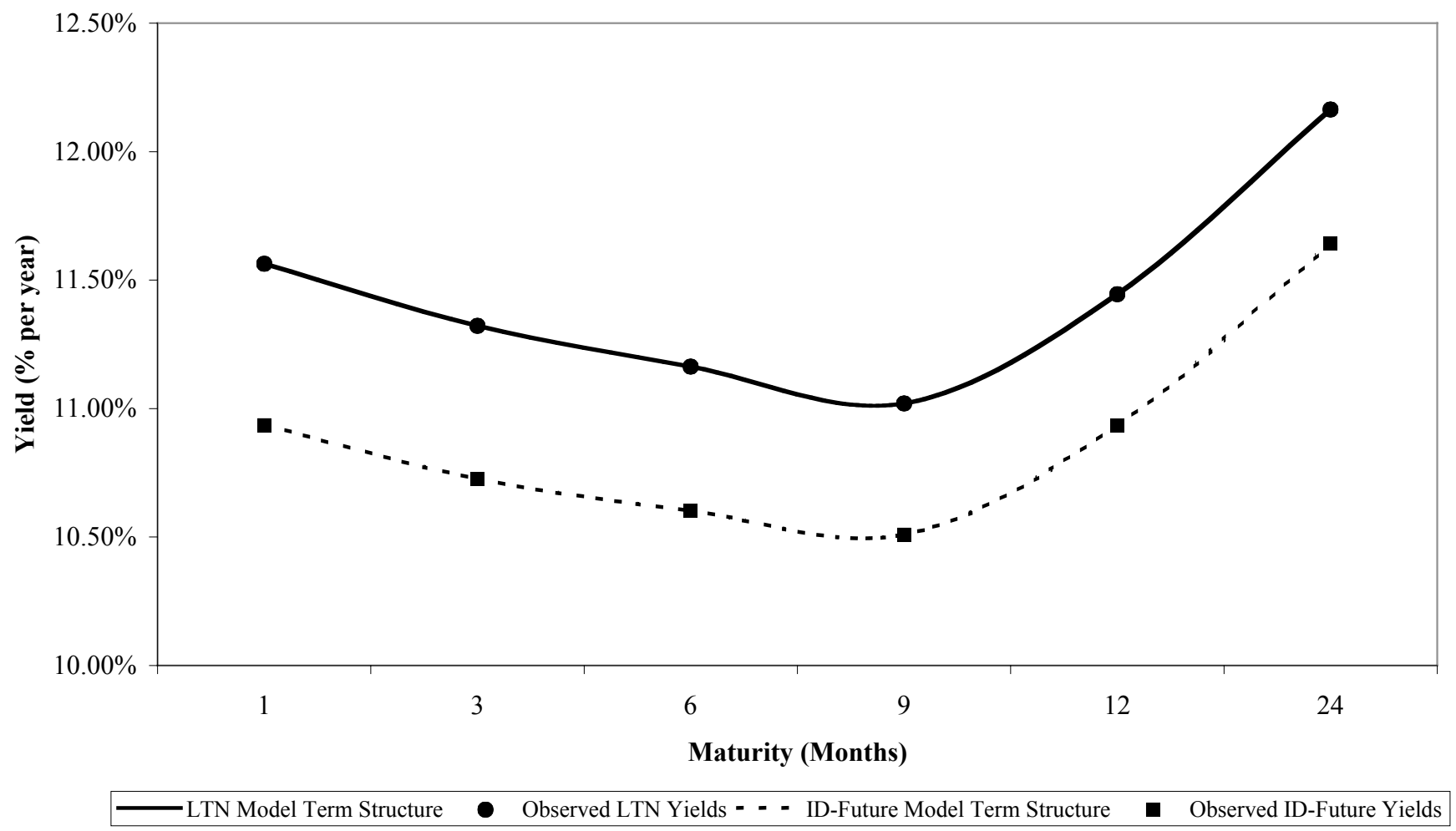

Fig. (6). Observed and Estimated Yields for Brazilian Government Bonds (LTN) and 1-Day Interbank Deposit Future (ID-Future) in December 2007.

al. [17] for markets with infrequent trading. We compare the term structure estimation of Brazilian government bonds (which is characterized by infrequent trading) and One-Day Interbank Deposit Futures (which is most liquid interest rate derivative in the Brazilian market).

Table 6. In-Sample and Out-of-Sample RMSE for Brazilian Government Bonds (LTN) in the Year 2007

\begin{tabular}{|c|c|c|}
\hline $\begin{array}{c}\text { Maturity Range } \\
\text { (Months) }\end{array}$ & $\begin{array}{c}\text { RMSE In-Sample } \\
\text { (\%) }\end{array}$ & $\begin{array}{c}\text { RMSE Out-of-Sample } \\
\text { (\%) }\end{array}$ \\
\hline \hline $0-1$ & 1.76 & 1.91 \\
\hline $1-3$ & 0.32 & 1.45 \\
\hline $3-6$ & 0.31 & 1.15 \\
\hline $6-9$ & 0.44 & 0.94 \\
\hline $9-12$ & 0.74 & 1.25 \\
\hline $12-24$ & 0.91 & 1.62 \\
\hline Total $(0-24)$ & 0.92 & 1.43 \\
\hline
\end{tabular}

Our results reveal that the model performs well in fitting observed yields of both government bonds and interest rates futures contracts. The measurement errors are significant for government bonds, but they are not significant for interest rate futures contracts.

All in-sample and out-of-sample errors are relatively low compared to the levels of Brazilian interest rates. Due to infrequent trading, the errors of government bonds are higher
Table 7. In-Sample and Out-of-Sample RMSE for 1-Day Interbank Deposit Future (ID-Future) in the Year 2007

\begin{tabular}{|c|c|c|}
\hline $\begin{array}{c}\text { Maturity Range } \\
\text { (Months) }\end{array}$ & $\begin{array}{c}\text { RMSE In-Sample } \\
\mathbf{( \% )}\end{array}$ & $\begin{array}{c}\text { RMSE Out-of-Sample } \\
\text { (\%) }\end{array}$ \\
\hline \hline $0-1$ & 0.28 & 1.90 \\
\hline $1-3$ & 0.25 & 1.30 \\
\hline $3-6$ & 0.42 & 1.06 \\
\hline $6-9$ & 0.42 & 0.85 \\
\hline $9-12$ & 0.72 & 0.97 \\
\hline $12-24$ & 1.00 & 1.56 \\
\hline Total (0-24) & 0.54 & 1.39 \\
\hline
\end{tabular}

than those of interest rates futures contracts. Nevertheless, the low out-of-sample error measures for government bonds suggest that the model can be useful in forecasting yield curves of assets with infrequent trading.

\section{REFERENCES}

[1] McCulloch J. Measuring the term structure of interest rates. J Bus 1971; 44: 19-31.

[2] McCulloch J. The tax adjusted yield curve. J Finance 1975; 30: 811-30.

[3] Vasicek O, Fong H. Term structure modeling using exponential splines. J Finance 1982; 37: 339-56.

[4] Nelson C, Siegel A. Parsimonious modeling of yield curves. J Bus 1987; 60: 473-89.

[5] Svensson L. Estimating and interpreting forward interest rates: Sweden 1992-1994. National Bureau of Economic Research Working Paper 1994. 
[6] Vasicek O. An equilibrium characterization of the term structure. J Financ Econ 1977; 5: 177-88.

[7] Brennan M, Schwartz E. A continuous time approach to the pricing of bonds. J Bank Finance 1979; 3: 133-55.

[8] Cox J, Ingersoll J, Ross S. A theory of the term structure of interest rates. Econometrica 1985; 53: 385-407.

[9] Ho T, Lee S. Term structure movements and the pricing of interestrate contingent claims. J Finance 1986; 51: 1011-29.

[10] Duffie D, Kan R. A yield-factor model of interest rates. Math Finance 1996; 6: 379-406.

[11] Chen R, Scott L. Maximum likelihood estimation for a multifactor equilibrium model of the term structure of interest rates. J Fixed Income 1993; 3: 14-31.

[12] Lund J. Econometric analysis of continuous-time arbitrage-free models of the term structure of interest rates. The Aarhus School of Business Working Paper 1994.

[13] Lund J. Non-linear Kalman filtering techniques for term-structure models. The Aarhus School of Business Working Paper 1997.

[14] Ball C, Torous W. Unit roots and the estimation of interest rate dynamics. J Empir Finance 1996; 3: 215-38.
[15] Duan J, Simonato J. Estimating and testing exponential-affine term structure models by Kalman filter. Rev Quant Finance Account 1999; 13: 111-35.

[16] Babbs S, Nowman K. Kalman filtering of generalized-Vasicek term structure models. J Financ Quant Anal 1999; 34: 115-130.

[17] Cortazar G, Schwartz E, Naranjo L. Term-structure estimation in markets with infrequent trading. Int J Finance Econ 2007; 12: 353 69 .

[18] De Jong F, Santa-Clara P. The dynamics of the forward interest rate curve: a formulation with state variables. J Financ Quant Anal 1999; 34: 131-57.

[19] De Jong F. Time-series and cross-section information in affine term structure models. J Bus Econ Stat 2000; 18: 300-314.

[20] SØrensen C. Modeling seasonality in agricultural commodity futures. J Futures Mark 2002; 22: 393-426.

[21] Litterman R, Scheinkman J. Common factors affecting bond returns. J Fixed Income 1991; 1: 54-61.

[22] Hamilton J. Time series analysis. Princeton, NJ. Princeton University Press.

(C) da Silva and da Silva; Licensee Bentham Open .

This is an open access article distributed under the terms of the Creative Commons Attribution License (http://creativecommons.org/licenses/by/2.5/), which permits unrestrictive use, distribution, and reproduction in any medium, provided the original work is properly cited. 